\title{
Cascade synthesis of uridine-5'-diphosphate glucuronic acid by coupling multiple whole cells expressing hyperthermophilic enzymes
}

\author{
Dan-Hua Meng ${ }^{1}$, Ran-Ran Du', Lu-Zhou Chen ${ }^{1}$, Meng-Ting Li', Fei Liu², Jin Hou ${ }^{3}$, Yi-Kang Shi ${ }^{4}$, \\ Feng-Shan Wang ${ }^{1,4}$ and Ju-Zheng Sheng ${ }^{1,4^{*}}$ (i)
}

\begin{abstract}
Background: Enzymatic glycan synthesis has leapt forward in recent years and a number of glucuronosyltransferase (EC 2.4.1.17) have been identified and prepared, which provides a guide to an efficient approach to prepare glycans containing glucuronic acid (GlcA) residues. The uridine 5'-diphosphate (UDP) activated form, UDP-GlcA, is the monosaccharide donor for these glucuronidation reactions.

Results: To produce UDP-GIcA in a cost-effective way, an efficient three-step cascade route was developed using whole cells expressing hyperthermophilic enzymes to afford UDP-GICA from starch. By coupling a coenzyme regeneration system with an appropriate expression level with UDP-glucose 6-dehydrogenase in a single strain, the cells were able to meet $\mathrm{NAD}^{+}$requirements. Without addition of exogenous $\mathrm{NAD}^{+}$, the reaction produced $1.3 \mathrm{~g} \mathrm{~L}^{-1} \mathrm{UDP}-\mathrm{GlcA}$, representing 100\% and 46\% conversion of UDP-Glc and UTP respectively. Finally, an anion exchange chromatography purification method was developed. UDP-GlcA was successfully obtained from the cascade system. The yield of UDPGlcA during purification was about $92.0 \%$.

Conclusions: This work built a de novo hyperthermophilic biosynthetic cascade into $E$. coli host cells, with the cells able to meet $\mathrm{NAD}^{+}$cofactor requirements and act as microbial factories for UDP-GlcA synthesis, which opens a door to large-scale production of cheaper UDP-GlcA.
\end{abstract}

Keywords: Biocatalysis, Whole cell synthesis, Nucleotide sugar, UDP-GlcA, Hyperthermophilic enzyme, NAD+ regeneration

\section{Introduction}

Glucuronic acid (GlcA) is one of the common building blocks of polysaccharides, proteoglycans and glycoglycerolipids [1]. GlcA can be transferred by glucuronosyltransferase (EC 2.4.1.17) to substrate molecules that contain oxygen, nitrogen, sulfur or carboxyl functional groups [2]. The uridine 5 -diphosphate (UDP) activated form, UDP-GlcA, is the monosaccharide donor for these glucuronidation reactions [2]. UDP-GlcA is one of nine nucleotide donor sugars used by glycosyltransferases in mammals. It is biosynthesized via two

\footnotetext{
*Correspondence: shengjuzheng@sdu.edu.cn

${ }^{1}$ Key Laboratory of Chemical Biology of Natural Products (Ministry of Education), School of Pharmaceutical Sciences, Shandong University, Jinan 250012, China

Full list of author information is available at the end of the article
}

pathways. One involves UDP-sugar pyrophosphorylase (EC:2.7.7.-, USP), catalyzed directly from the respective GlcA-1-phosphates (GlcA1P). The other pathway, common in bacteria and animals, is synthesis of UDP-GlcA from UDP-glucose (UDP-Glc) by UDP-glucose 6-dehydrogenase (EC 1.1.1.22, UDH) using nicotinamide adenine dinucleotide $\left(\mathrm{NAD}^{+}\right)$as a cofactor $[3,4]$.

Understanding and application of enzymatic glycan synthesis has leapt forward in recent years [5-8]. Even an automated system for oligosaccharides synthesis is going to become possible $[9,10]$. Meanwhile, a number of glycosyltransferases using UDP-GlcA as sugar donor have been identified and prepared [11-15], which provides a guide to an efficient approach to prepare glycans containing GlcA residues [16-19]. As the types and preparation 
scale of these oligosaccharides increase, the demand for UDP-GlcA is also increasing. However, natural nucleotide sugars are generally only present in plant and mammalian cells at pmol or nmol concentrations [20,21], which is too low for them to be obtained directly. Two enzymatic approaches for UDP-GlcA synthesis from monosaccharide (Glc or GlcA) via in vitro multiple-enzyme pathways have been developed by Xi Chen's group [22, 23]. In 2013, UDPGlcA was prepared through a dehydrogenation step [22]. The newer system, reported in 2015, avoided the use of the expensive $\mathrm{NAD}^{+}$cofactor via de novo synthesis from GlcA by Arabidopsis thaliana glucuronokinase and USP [23]. These systems have been successfully employed in oligosaccharide synthesis. However, the required purification steps limit the synthetic effectiveness and scale of the process, and push up the cost. The use of enzyme-cascades in whole cells is an effective strategy to produce UDP-GlcA in a more cost-effective way, because of the benefits of decreasing enzyme purification costs and potentially providing biochemical cofactors via endogenous pathways [24].

Therefore, we propose an added-cofactor-free wholecell catalytic approach that converts starch to UDP-GlcA (Fig. 1). This pathway contains two steps: (1) phosphorylation of starch to glucose 1-phosphate (G1P) catalyzed by $\alpha$-glucan phosphorylase; (2) conversion of G1P to UDPGlc catalyzed by USP; and (3) dehydrogenation of UDPGlc to UDP-GlcA catalyzed by UDH. Finally, an efficient three-step cascade route was developed using whole cells expressing hyperthermophilic enzymes, and valuable UDPGlcA was produced in this cost-effective way from starch.

\section{Results and discussion}

\section{Hyperthermophilic enzymes were soluble overexpressed} well in whole-cell biocatalysts

To develop an efficient three-step cascade route and produce valuable UDP-GlcA from starch in a cost-effective way, thermophilic enzymes from hyperthermophilic microorganisms were employed. Since the activities of endogenous enzymes of Escherichia coli were sharply decreased at high temperature $\left(>70{ }^{\circ} \mathrm{C}\right)[25]$, and which avoids unwanted
G1P, UTP or UDP-sugar consumption catalyzed by these endogenous enzymes. In addition, the molecular weight of the initial substrate (starch) is high. The permeability of the membrane of recombinant cells could be increased at high temperature, resulting in an increased probability of this substrates interacting with the catalytic enzymes.

The efficiency of formation of UDP-Glc is critical to the performance of our proposed cascade synthesis approach. One thermophilic USP, named StUSP, from Sulfolobus tokodaii, has been identified [26], and was used as the catalyst in this study. USPs, including StUSP, convert monosaccharides to UDP-sugars in a reversible reaction [26]. Therefore, to quantify the catalytic efficiency at high temperate, the kinetic parameters of StUSP and its conversion efficiency of G1P to UDP-Glc were determined (Additional file 1: Table S1 and Figure S1), demonstrating that this enzyme shows high specific activity and an acceptable level of to G1P at $80^{\circ} \mathrm{C}$.

Another three thermophilic enzymes- $\alpha$-glucan phosphorylase (Tm $\alpha \mathrm{GP})$ from Thermotoga maritima [27], PiUDH from Pyrobaculum islandicum [28], and TkNOX from Thermococcus kodakarensis [29] - were selected for use in this study because of their high thermostability and specific activities. Expression of these three enzymes, plus StUSP, encoded by codon-optimized genes, was induced with isopropyl- $\beta$-D-1-thiogalactopyranoside and SDS-PAGE analysis confirmed that all the enzymes were soluble and overexpressed well in E. coli (Fig. 2). It is worth noting that folding of thermophilic enzymes can be impaired in a mesophilic cytoplasmic environment by a number of factors, including temperature, but also by more subtle effects, such as translation kinetics of native versus optimized genes [30, 31].

\section{Whole-cell synthesis of UDP-GIc by a hybrid cascade system}

As illustrated in Fig. 3, a hybrid cascade system was used, comprised of two separate whole cell catalysts containing Tm $\alpha$ GP and StUSP, respectively. First, a series of assays was carried out to determine the effects of temperature,

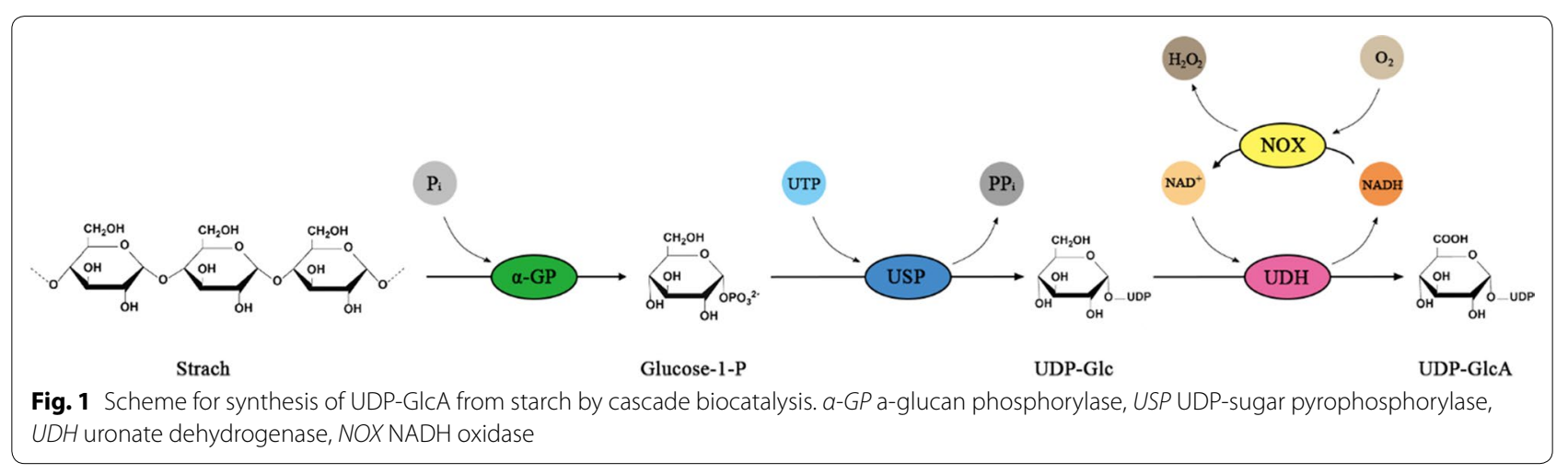



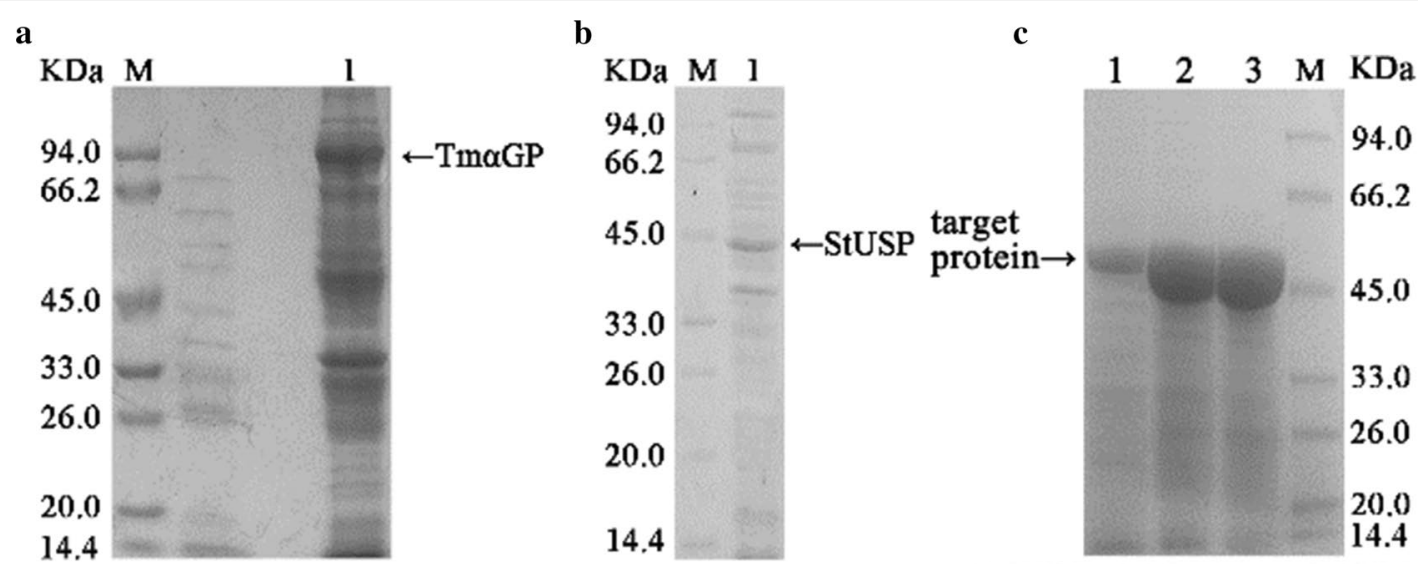

1.TkNOX 2.PiUDH 3.TkNOX-PiUDH

Fig. 2 SDS-PAGE analysis of recombinant thermostable enzyme expression in whole cell catalysts. Harvested cells were heated at $80^{\circ} \mathrm{C}$ for $20 \mathrm{~min}$ and then centrifuged at $12,000 \times g$, then the supernatants were detected by $10 \%$ SDS-PAGE

$\mathrm{pH}$ and reaction time on the enzyme activity and stability of the whole-cell TmaGP-containing system when a preheated $5 \%(\mathrm{w} / \mathrm{v})$ solution of soluble starch was used as substrate (Additional file 1: Figure S2). Gratifyingly, in the optimal conditions, the concentration of G1P in the reaction mixture reached approximately $40 \mathrm{mM}$ (Table 1 , entry 1); and $1 \mathrm{~g}$ G1P could be produced by the cells isolated from a $0.81 \mathrm{~L}$ fermentation. The optimal temperature was around $70{ }^{\circ} \mathrm{C}$, close to the desired temperature $\left(80^{\circ} \mathrm{C}\right)$ of the follow-up step using the whole-cell StUSP system. These results thereby demonstrated the utility and potential of whole cells containing Tm $\alpha$ GP in a cascade system for the production of UDP-Glc.

Next, whole cells containing StUSP were introduced into the above mixture to produce UDP-Glc. The optimal conditions for this were determined (Additional file 1: Figures S3-S7): the optimal temperature was around $80{ }^{\circ} \mathrm{C}$, which is consistent with data for purified StUSP; the optimal $\mathrm{pH}$ was around 9.0, obviously greater than that $(\sim 7.5)$ for the purified enzyme. It appears that an alkaline environment makes the cell membranes more permeable to substrate, and benefits overall UDP-Glc synthesis in our system. The product of the TmaGP-catalyzed step should be diluted fourfold with phosphate buffer and the $\mathrm{pH}$ adjusted to 9.0, making the concentration of G1P approximately $10 \mathrm{mM}$. The price of UTP is higher than the cost of preparation of G1P and the whole-cell StUSP catalyst, thus, more efficient use of UTP will lead to better economic performance of our proposed cascade synthesis approach. However, the conversion of UTP is difficult to exceed $50 \%$, even if the amount of whole cells and the ratio of UTP to G1P was increased in the reaction system (Additional file 1: Figure S7). This conclusion is consistent with data for in vitro reaction catalyzed by purified StUSP, demonstrating that the reversible nature of the USP reaction is likely one of the limiting factors affecting the performance of UDP-sugar synthesis, and this needs to be addressed in the future. USP mutants created by protein engineering could be a strategy to address this issue. The product concentration in our system was determined by polyamine-based anion exchange-high-performance liquid chromatography (PAMN-HPLC) (Fig. 4a) [32], and the identity of UDP-Glc was confirmed by electrospray ionizationmass spectrometry (ESI-MS) as described previously [33] (Fig. 4b). We obtained $4.6 \mathrm{mM}$ UDP-Glc in the reaction mixture, with $46 \%$ conversion of UTP (Table 1 , entry 2).

\section{Synthesis of UDP-GICA using an added-cofactor-free whole-cell catalytic approach}

Whole cells containing both the thermophilic UDP-Glc dehydrogenase $(\mathrm{PiUDH})$ and an $\mathrm{NAD}^{+}$regeneration system (TkNOX) were introduced into the reaction mixture of step 2, resulting in an added-cofactor-free whole-cell catalytic approach. $\mathrm{NAD}^{+}$, an oxidizing cofactor of UDPGlc dehydrogenase, accepts electrons from UDP-Glc and becomes reduced to NADH. NAD ${ }^{+}$is a costly compound if added to synthesis systems. A series of assays was carried out to determine the effects of $\mathrm{NAD}^{+}$concentration, as well as other reaction conditions, on the UDP-GlcA yield (Additional file 1: Figure S8-S11). The reaction mixture from the Tm $\alpha$ GP and StUSP cascade system was used as substrate. There was nearly 50\% conversion of UDP-Glc to UDP-GlcA in reaction without addition of exogenous $\mathrm{NAD}^{+}$(Table 1, entry 3 and Additional file 1: Figure S11), 

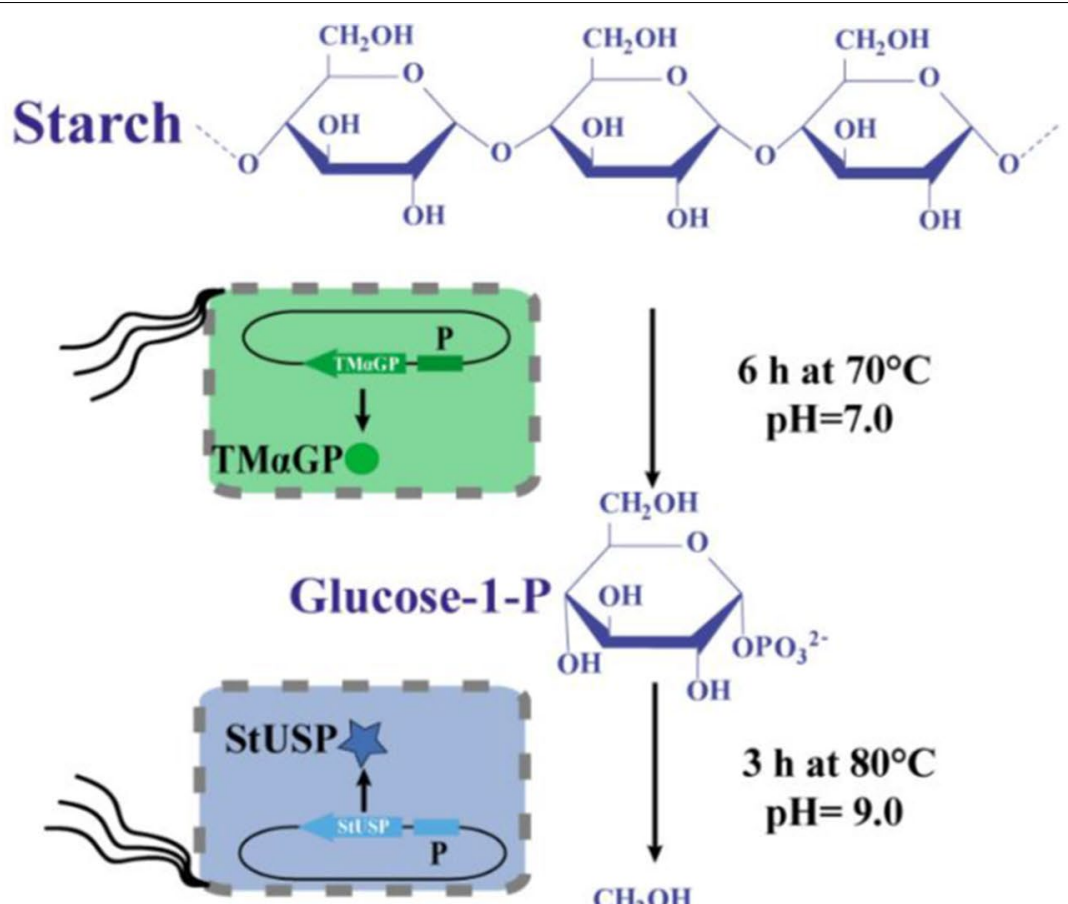

$\mathrm{OH}$
$3 \mathrm{~h}$ at $80^{\circ} \mathrm{C}$
$\mathrm{pH}=\mathbf{9 . 0}$
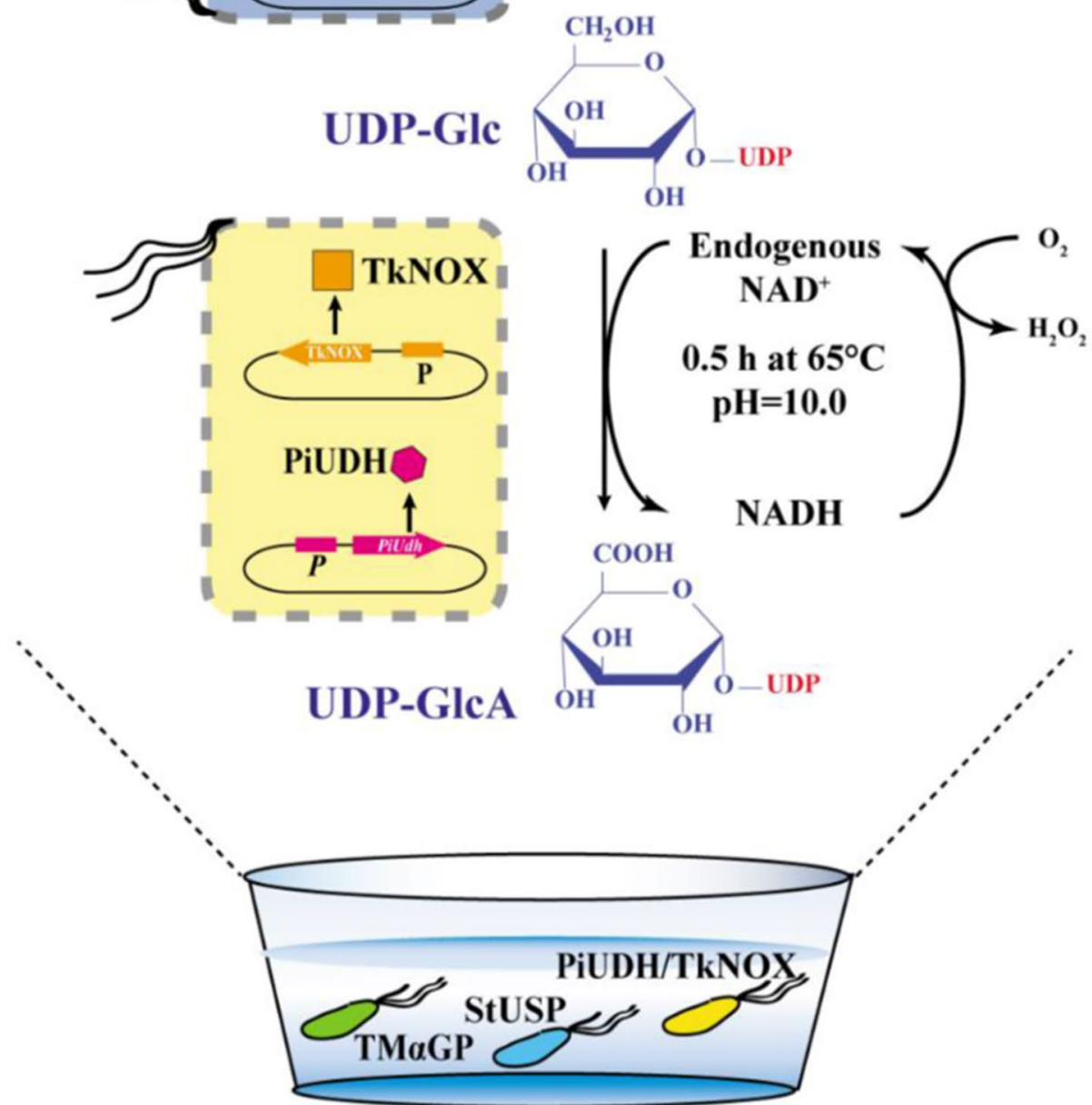

Fig. 3 Scheme for the three-step cascade route using whole cells expressing hyperthermophilic enzymes to afford UDP-GICA from starch 


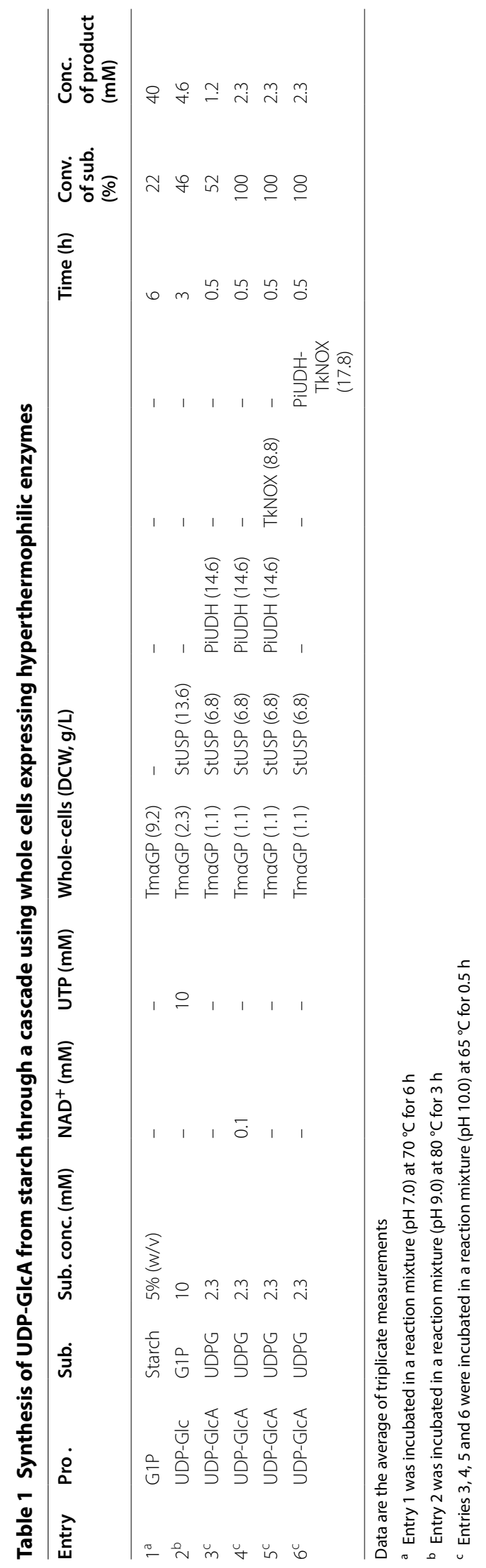



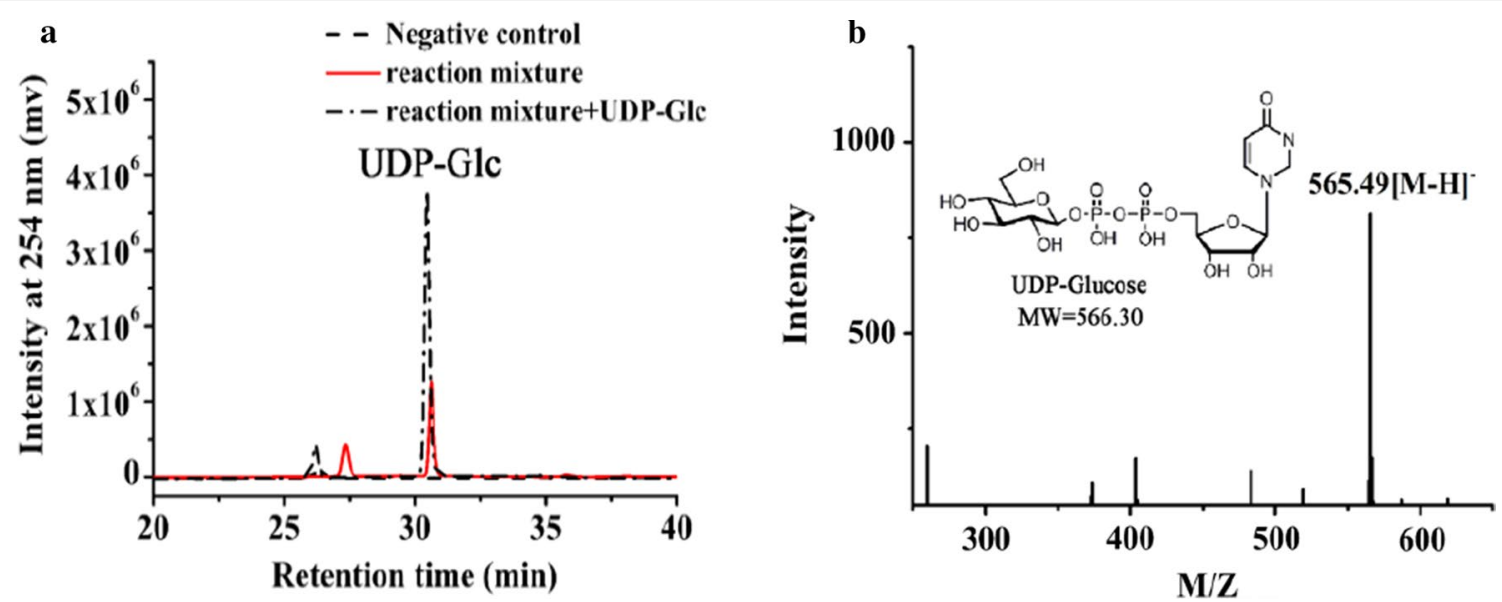

Fig. 4 Analysis of UDP-Glc formation. a The supernatant of reaction catalyzed by the hybrid cascade system comprised of separate whole cell catalysts expressing TmaGP and StUSP, in the optimized conditions described above, was assayed by PAMN-HPLC. b ESI-MS spectrum of product UDP-Glc. The supernatant of reaction catalyzed by the hybrid cascade system comprised of separate whole cell catalysts expressing TmaGP and StUSP, in the optimized conditions described above, was assayed by MS after desalting using a P2 column
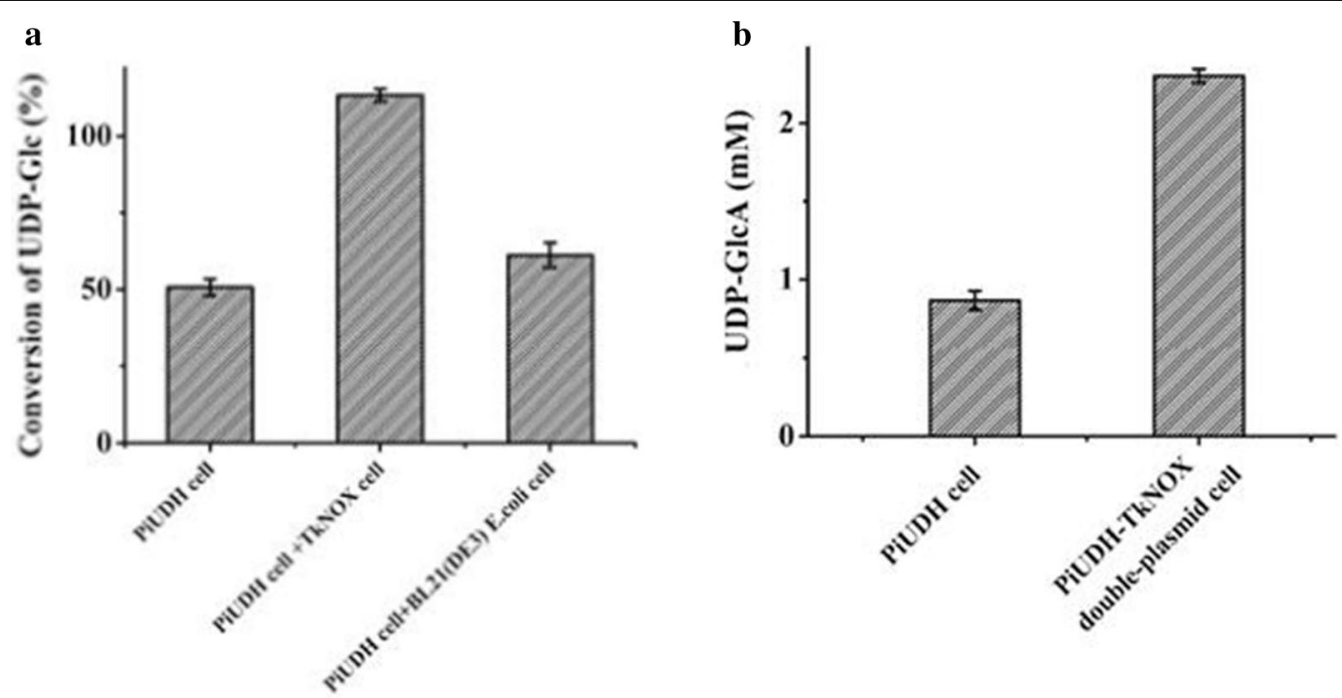

Fig. 5 Effect of $\mathrm{NAD}^{+}$regeneration system on UDP-GICA formation. a BL21-PiUDH, BL21-TkNOX and plasmid-free E. coli BL21 (DE3) cells were fermented and used as catalysts. Initially, BL21-PiUDH cells were incubated in a mixture containing $2.3 \mathrm{mM} U \mathrm{UDP}-\mathrm{Glc}, 0 \mathrm{mM}$ NAD ${ }^{+}$and $200 \mathrm{mM}$ sodium phosphate ( $\mathrm{pH} 10)$. Then, groups containing the same components, and an additional BL21-TkNOX or BL21 cells respectively, were introduced into the reactions. These mixtures were incubated for $0.5 \mathrm{~h}$ and supernatants were detected by HPLC. $\mathbf{b}$ BL21-PiUDH and BL21-PiUDH-TkNOX cells were fermented and used as catalysts. BL21-PiUDH or BL21-PiUDH-TkNOX cells were incubated with $2.3 \mathrm{mM} \mathrm{UDP-Glc,}$ without extra supplementation, at $65^{\circ} \mathrm{C}$ for $0.5 \mathrm{~h}$. These mixtures were incubated for $0.5 \mathrm{~h}$ and supernatants were detected by HPLC. And bars indicate the range of assay results from three different batches

which indicated that intracellular $\mathrm{NAD}^{+}$played a role in the dehydrogenase reaction. The synthetic efficiency showed a positive correlation with the concentration of $\mathrm{NAD}^{+}$in the thermophilic system, and UDP-Glc could be fully converted into UDP-GlcA when enough NAD ${ }^{+}$ was added (Table 1, entry 4 and Additional file 1: Figure S11). Therefore, a thermophilic $\mathrm{NAD}^{+}$regeneration system was employed to make our approach added-cofactorfree [34]. Firstly, whole cells overexpressing TkNOX were constructed (Fig. 1d), and its $\mathrm{NAD}^{+}$regeneration role was confirmed. The UDP-Glc conversion reached nearly $100 \%$ in the hybrid cascade system containing two separate types of whole cells expressing TkNOX and PiUDH respectively (Table 1, entry 5 and Fig. 5a). The number of TkNOX-containing cells in this system was approximately half that of the PiUDH-containing cells. Both genes were expressed under the control of the same promotor (the T7 promoter), and in the same plasmid system (the pET system). 

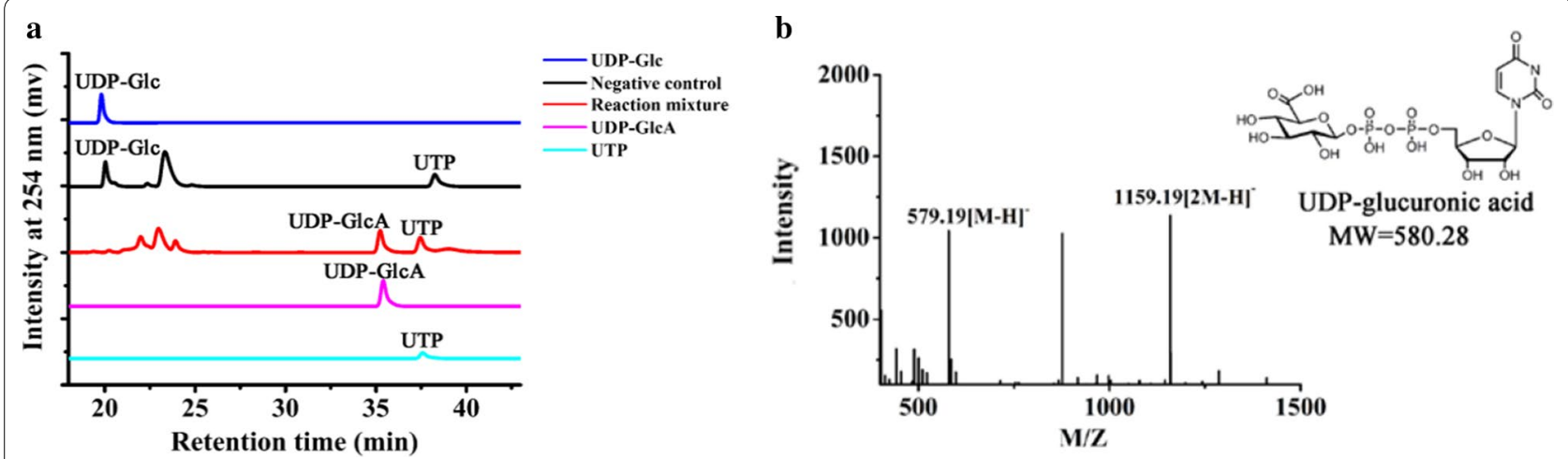

Fig. 6 Analysis of UDP-GICA formation. a The supernatant of the three-step cascade reaction was assayed by PAMN-HPLC. $\mathbf{b}$ ESI-MS of product UDP-GICA. The supernatant of the three-step cascade reaction was assayed by MS after desalting using a P2 column

Therefore, next, a low-copy-number plasmid with the T7 promoter, pACYCDuet-1, was used to express TkNOX in PiUDH-expressing cells, resulting in a strain coexpressing these two enzymes (Figs. 1e and 5b). Then, the optimal conditions for this whole cell catalytic system were determined (Additional file 1: Figure S12), and the identity of the synthetic products was confirmed by (PAMN)-HPLC and ESI-MS (Fig. 6). We obtained $1.3 \mathrm{gL}^{-1} \mathrm{UDP}-\mathrm{GlcA}$ without addition of exogenous $\mathrm{NAD}^{+}$, with $100 \%$ conversion of UDP-Glc (Table 1, entry 6).

\section{Purification of UDP-GICA from the cascade system}

We developed a purification method for UDP-GlcA from the cascade system, based on anion exchange chromatography. Four peaks were seen as the purification proceeded (Fig. 7a). The fractions were desalted and subjected to HPLC and ESI-MS analysis. A compound with a molecular mass of 577.23 Da was identified in fractions of the fourth peak eluted from the anion exchange column, which is very close to the calculated molecular mass of UDP-GlcA, 577.26 Da (Fig. 7b). In high-resolution HPLC, this product showed a single symmetric peak and eluted at $42 \mathrm{~min}$ (Fig. 7c). These results suggested that UDP-GlcA was successfully obtained. The yield of UDP-GlcA during purification was about $92.0 \%$ (i.e., loss of $<10 \%)$. This method can also be applied to purify UDP-Glc from the products of step 1 (unpublished data).

\section{Conclusions}

This work built a de novo hyperthermophilic biosynthetic cascade into E. coli host cells, with the cells able to meet $\mathrm{NAD}^{+}$cofactor requirements and act as microbial factories for UDP-GlcA synthesis. From simple starting materials, $1 \mathrm{~g}$ of valuable UDP-GlcA could be obtained by using approximately $1.8 \mathrm{~g}$ UTP, suggesting this three-step cascade route opens a door to large-scale production of UDP-GlcA at lower cost than previous methods.
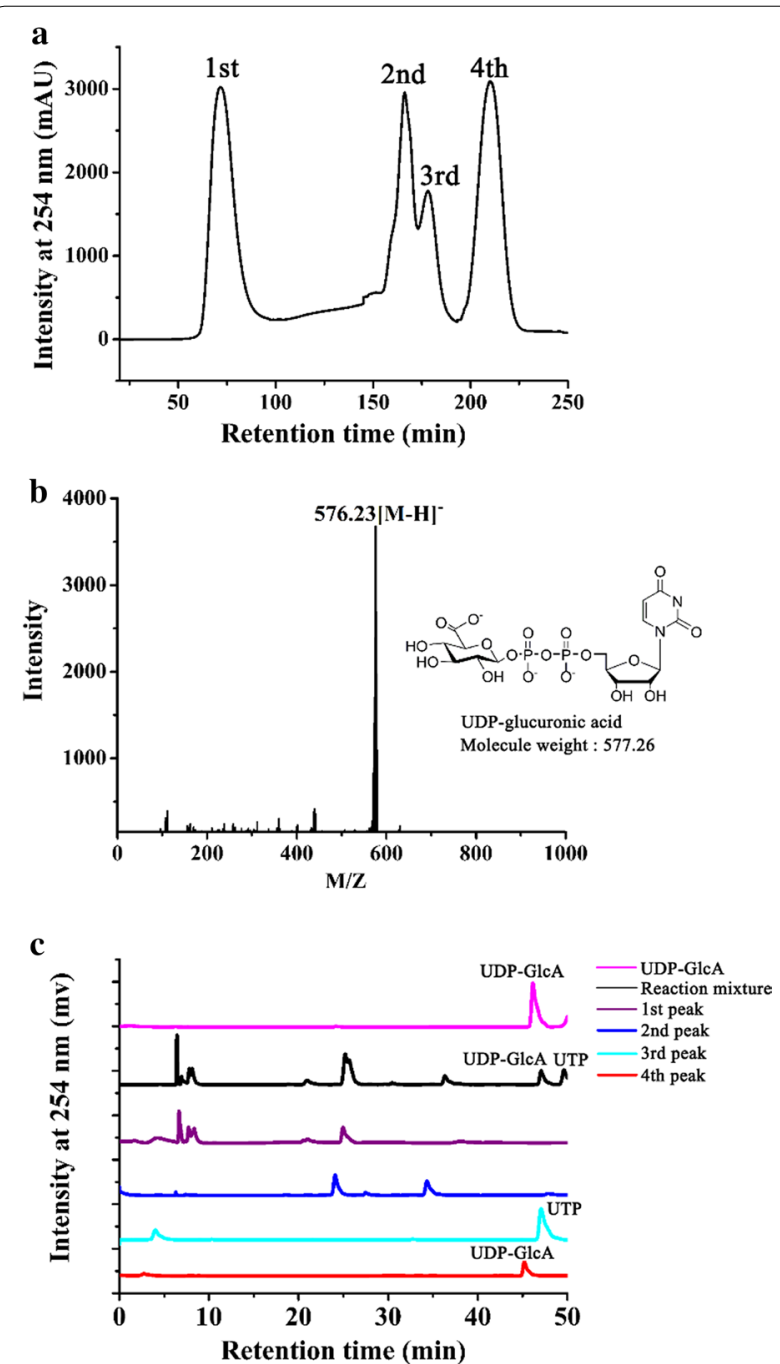

Fig. 7 Purification of UDP-GICA. a Anion exchange chromatography profile of the products of the three-step cascade. $\mathbf{b}$ ESI-MS spectrum of the fourth peak eluted from the anion exchange column. c PAMN-HPLC of fractions eluted from the anion exchange column, as well as the reaction mixture and a UDP-GICA standard 


\section{Methods}

\section{General procedures for preparation of whole-cell} biocatalysts

The plasmids involved in the construction of recombinant Escherichia coli cells and the strains are listed in Table 2.

The Tm $\alpha$ GP gene (GenBank accession number NC_000853.1), StUSP gene (GenBank accession number NC_003106.2), PiUDH gene (GenBank accession number NC_008701.1), and TkNOX gene (GenBank accession number NC_006624.1) with a 5'-His tag fragments were synthesized with codon optimization for gene expression in E. coli by GenScript Inc. (Nanjing, China), respectively. Then these enzymes were recombinant expression in $E$. coli BL21 (DE3) cells as soluble N-His6-tagged fusion proteins and purified by appropriate affinity chromatography, as described in Additional file 1.

The $T k N O X$ gene DNA fragment was also inserted into vector pACYC Duet-1 (Novagen). This plasmid was named pACYC Duet1-tknox, and was introduced into E. coli $\mathrm{BL} 21-\mathrm{PiUDH}$, producing recombinant strain BL21-PiUDH-TkNOX.

These recombinant strains were grown at $37{ }^{\circ} \mathrm{C}$ in high density fermentation medium with $100 \mu \mathrm{g} / \mathrm{mL}$ ampicillin, and only PiUDH-TkNOX double-plasmid recombinant $E$. coli use two antibiotics, $100 \mu \mathrm{g} / \mathrm{mL}$ ampicillin and $34 \mu \mathrm{g} /$ $\mathrm{mL}$ chloromycetin. In fermentation process, $\mathrm{pH}$ should be controlled to 7.0, stirring speed was $500 \mathrm{rpm}$, and dissolved oxygen content should be controlled to $25 \%$ of maximum

\section{Table 2 Plasmids and strains used in this study}

\begin{tabular}{|c|c|c|}
\hline Strain or plasmid & Characteristics & Source \\
\hline \multicolumn{3}{|l|}{ E. coli strains } \\
\hline $\mathrm{DH} 5 \mathrm{a}$ & & Thermo Fisher \\
\hline BL21 (DE3) & & Thermo Fisher \\
\hline BL21-TmaGP & pET20b-TmaGP & This work \\
\hline BL21-StUSP & pET21b-StUSP & This work \\
\hline BL21-PiUDH & pET15b-PiUDH & This work \\
\hline BL21-TkNOX & pET21b-TkNOX & This work \\
\hline BL21-PiUDH-TkNOX & $\begin{array}{l}\text { pET15b-PiUDH and pACYC- } \\
\text { Duet1-TkNOX }\end{array}$ & This work \\
\hline \multicolumn{3}{|l|}{ Plasmids } \\
\hline pET20b(+) & Expression vector, $A p^{R}$ & Novagen \\
\hline pET21b(+) & Expression vector, $A p^{R}$ & Novagen \\
\hline pET15b & Expression vector, $A p^{R}$ & Novagen \\
\hline pACYCDuet-1 & Expression vector, $\mathrm{Cm}^{\mathrm{R}}$ & Novagen \\
\hline pET20b-TmaGP & Expression vector of TmaGP & This work \\
\hline pET21b-StUSP & Expression vector of ST0452 & This work \\
\hline pET15b-PiUDH & Expression vector of PiUDH & This work \\
\hline pET20b-TkNOX & Expression vector of TkNOX & This work \\
\hline $\begin{array}{l}\text { pACYC Duet1- } \\
\text { TkNOX }\end{array}$ & Expression vector of TkNOX & This work \\
\hline
\end{tabular}

value of dissolved oxygen content. Cells were then cultured until optical density at $600 \mathrm{~nm}\left(\mathrm{OD}_{600}\right)$ increased to $15-20$. $1 \mathrm{mM}$ isopropyl-b-D-thiogalactopyranoside (IPTG) was used to induce E. coli at $22^{\circ} \mathrm{C}$ for more than $20 \mathrm{~h}$.

\section{Optimization of whole-cell synthesis of G1P and final optimized conditions}

Reaction was in a $500 \mu \mathrm{L}$ mixture including $5 \%(\mathrm{w} / \mathrm{v})$ soluble starch, 0.7 M potassium phosphate buffer (pH7.0) and about $3.3 \mathrm{mg}$ (DCW) cells expressing Tm $\alpha$ GP. Reaction was terminated by chilling on ice for $5 \mathrm{~min}$, and then the mixture was centrifuged at $12,000 \times g$ for $20 \mathrm{~min}$ at $4{ }^{\circ} \mathrm{C}$. Then, the supernatant was precipitated with $0.7 \mathrm{M}$ $\mathrm{Ca}^{2+}\left(\mathrm{CaCl}_{2}\right)$ to remove phosphate and then diluted to twice the original volume before detection by thin-layer chromatography (TLC). TLC analysis was performed on TLC Silica gel $60 \mathrm{~F}_{254}$ (Merck KGA, Germany), developed by $n$-butanol:acetic acid: $\mathrm{ddH}_{2} \mathrm{O}(2: 1: 1, \mathrm{v} / \mathrm{v})$, and subsequently stained with anisaldehyde. G1P shows as a dark spot after being stained. As shown in Additional file 1: Figure S2, incubating at $70{ }^{\circ} \mathrm{C}$ for $6 \mathrm{~h}$ at $\mathrm{pH} 7.0$ was determined to be optimal for TmaGP in whole-cell catalysis.

\section{Catalytic analysis of purified StUSP}

Strain BL21-StUSP was cultured, and treated with $0.2 \mathrm{mM}$ IPTG for $18-20 \mathrm{~h}$ at $22^{\circ} \mathrm{C}$ to induce expression of StUSP. Then, N-terminally His-tagged recombinant StUSP was purified using $\mathrm{Ni}^{2+}$-affinity resin, and incubated with substrates at 80 or $37{ }^{\circ} \mathrm{C}$. The forward reaction of StUSP was performed in a $200-\mu \mathrm{L}$ mixture including $2 \mathrm{mM} \mathrm{G1P}$, $20 \mathrm{mM} \mathrm{MgCl}$, $50 \mathrm{mM}$ Tris- $\mathrm{HCl}$ (pH 7.5), 3 mM UTP, and $1 \mu \mathrm{g}$ purified enzyme. The reverse reaction was performed in a $200-\mu \mathrm{L}$ mixture including $0.5 \mathrm{mM}$ UDP-Glc, $2 \mathrm{mM}$ $\mathrm{MgCl}_{2}, 50 \mathrm{mM}$ Tris- $\mathrm{HCl}$ (pH 7.5), $1 \mathrm{mM}$ pyrophosphate, and $1 \mu \mathrm{g}$ of purified enzyme. After the reactions reached equilibrium, the products were resolved via (PAMN)HPLC. The absorbance at $254 \mathrm{~nm}$, which corresponds to the UDP group, was used to monitor the products.

To measure the $K_{m}$ and $V_{\max }$ values of the forward reaction, reactions were carried out at G1P concentrations varying from 0.2 to $3 \mathrm{mM}$ in a buffer described above. Six time-response samples were collected for donor concentrations and obtained by (PAMN)-HPLC, then fitted to the Michaelis-Menten equation.

\section{Optimization of whole-cell synthesis of UDP-GIc}

To determine the effects of temperature on UDP-Glc formation, BL21-TmaGP cells (12.5 mg DCW per milliliter) were incubated in a mixture consisting of $2 \mathrm{mM} \mathrm{G1P}$, $3 \mathrm{mM}$ UTP, $20 \mathrm{mM} \mathrm{Mg}^{2+}$, and $50 \mathrm{mM}$ sodium phosphate (pH9.0) at $60,70,75,80,85,90$, and $95^{\circ} \mathrm{C}$, respectively. The reactions were terminated by chilling on ice for $5 \mathrm{~min}$, centrifuged at $12,000 \mathrm{rpm}$ for $20 \mathrm{~min}$ at $4{ }^{\circ} \mathrm{C}$, and 
the supernatants were detected by HPLC. Reactions were performed to determine effect of the $\mathrm{pH}$ (in the range $2.5-12)$, reaction time $(0,5,10,30,40,60,80,120,180$ and $240 \mathrm{~min})$, and the dry cell weight added (0, 0.09, 0.23, $0.46,0.91,1.37$ and $1.82 \mathrm{mg}$ ) similar to that described for the optimized temperature assay. Each group of the reaction was performed using three paralleled assays.

\section{Optimization of whole-cell synthesis of UDP-GIcA}

The effects of temperature of whole-cell synthesis of UDP-GlcA were investigated using UDP-Glc as substrate. BL21-PiUDH cells (17.5 mg DCW per milliliter) were incubated in a mixture consisting of $2.3 \mathrm{mM}$ UDP-Glc, $1.5 \mathrm{mM} \mathrm{NAD}^{+}$and $200 \mathrm{mM}$ sodium phosphate (pH10) at $50,60,65,70,75,80$, and $85^{\circ} \mathrm{C}$, respectively. Similarly, multiple reactions with various $\mathrm{pH}$ values, reaction time, dry cell weight added, and cofactor concentration were carried out simultaneously with all of the other components fixed. Each group of the reaction was performed using three paralleled assays.

\section{$\mathrm{NAD}^{+} / \mathrm{NADH}$ regeneration system}

BL21-PiUDH, BL21-TkNOX and plasmid-free E. coli BL21 (DE3) cells were fermented and used as catalysts. Initially, BL21-PiUDH cells (14.5 mg DCW per milliliter) were incubated in a mixture containing $2.3 \mathrm{mM}$ UDP-Glc, $0 \mathrm{mM} \mathrm{NAD}^{+}$and $200 \mathrm{mM}$ sodium phosphate (pH10). Then, groups containing the same components, and an additional BL21-TkNOX or BL21 cells (7.25 mg DCW per milliliter) respectively, were introduced into the reactions. In addition, BL21-PiUDH and BL21PiUDH-TkNOX cells were fermented and used as catalysts. BL21-PiUDH or BL21-PiUDH-TkNOX cells (17.5 DCW per milliliter) were incubated with $2.3 \mathrm{mM}$ UDPGlc, without extra supplementation, at $65{ }^{\circ} \mathrm{C}$ for $0.5 \mathrm{~h}$. The supernatants were detected by HPLC.

\section{Effect of dry cell weight addition of BL21-PiUDH-TkNOX cells on UDP-GIcA formation}

UDP-Glc $(2.3 \mathrm{mM})$ was respectively incubated with 0 , $0.08,0.16,0.40,0.79,1.19,1.58,2.37,3.17,4.75,6.33$ and $7.12 \mathrm{mg}$ BL21-PiUDH-TkNOX cells (DCW), without extra supplementation in $400 \mu \mathrm{L}$ mixture, at $65{ }^{\circ} \mathrm{C}$ for $0.5 \mathrm{~h}$. The supernatants were detected by HPLC. All experiments were repeated three times.

\section{Purification of UDP-GICA}

The purification process was performed using an Äkta Avant 150 (GE Healthcare Bio-Sciences AB, Uppsala, Sweden) with a Q-Sepharose Fast-Flow column, and the $\mathrm{pH}$ of the reaction mixture and the buffers was adjusted to 3.7. The column was first eluted with a linear gradient of $\mathrm{NaCl}$ from 0 to $0.25 \mathrm{M}$ over one column volume, and then with $0.25 \mathrm{M} \mathrm{NaCl}$ for one column volume, and finally with one column volume of $0.3 \mathrm{M} \mathrm{NaCl}$. The flow rate throughout the process was $2.5 \mathrm{~mL} / \mathrm{min}$.

\section{High-resolution HPLC analysis}

PAMN-HPLC analysis was performed using a Shimadzu HPLC instrument (Tokyo, Japan) equipped with a YMC-Pack Polyamine II column $(250 \times 4.6 \mathrm{~mm}$; Shimogyo-ku, Kyoto, Japan) [14]. The column was eluted at a flow rate of $0.5 \mathrm{~mL} / \mathrm{min}$, with a linear gradient of $\mathrm{KH}_{2} \mathrm{PO}_{4}$ from 0 to $0.6 \mathrm{M}$ over $40 \mathrm{~min}$ for UDP-Glc detection, and a linear gradient of $\mathrm{KH}_{2} \mathrm{PO}_{4}$ from 0.2 to $0.6 \mathrm{M}$ over $40 \mathrm{~min}$ for UDP-GlcA detection. The absorbance at $254 \mathrm{~nm}$, from the UDP group, was used to monitor the products.

\section{Mass spectrometry}

MS analysis was performed on a Thermo LCQ Deca mass spectrometer. The experiments were performed using negative ionization mode with a spray voltage of $3 \mathrm{kV}$ and a capillary temperature of $275^{\circ} \mathrm{C}$ [33]. MS data were acquired and processed using Xcalibur 1.3 software.

\section{Additional file}

Additional file 1: Table S1. Effect of temperature on kinetics of purified StUSP. Figure S1. Kinetic parameters of, and substrate conversion by, purified StUSP. Determination of kinetic parameters of StUSP at $37^{\circ} \mathrm{C}(\mathrm{A})$ and $80^{\circ} \mathrm{C}$ (B). G1P was used as substrate to determine the kinetic parameters of purified StUSP. The amounts of product UDP-Glc were determined by PAMN-HPLC. (C) Substrate conversion in activity assays of purified StUSP at 37 and $80^{\circ} \mathrm{C}$. All data represent the average of three independent determinations. Figure S2. Optimization of the reaction catalyzed by whole cells expressing TmaGP. A, Temperature optimization. Lanes 1 to 5, reactions were carried out at $50,60,70,80$, and $90^{\circ} \mathrm{C}$, respectively. Lane 6, G1P standard (20 mM). B, TLC assays of whole-cell TmaGP catalysis at various $\mathrm{pHs}$. Lanes 1 to 10 , reactions were carried out in a mixture adjusted to $\mathrm{pH} 3,4,5,6,7,8,9,10,11$, and 12, respectively; Lane 6 and 11, G1P standard (20 mM). C, Effect of reaction time on G1P formation. Lanes 1 to 11 , reactions were performed for $0,5,10,20,30,60,120,180,360,660$, and 960 min, respectively; Lane 12, G1P (20 mM). Figure S3. Analysis of StUSP catalysis in whole-cells by temperature. BL21-TmaGP cells (12.5 mg DCW per milliliter) were incubated in a mixture consisting of $2 \mathrm{mM} \mathrm{G} 1 \mathrm{P}, 3 \mathrm{mM}$ UTP, $20 \mathrm{mM} \mathrm{Mg}^{2+}$, and $50 \mathrm{mM}$ sodium phosphate (pH9.0) at 60, 70, 75, 80, 85,90 , and $95^{\circ} \mathrm{C}$, respectively. The reactions were terminated by chilling on ice for $5 \mathrm{~min}$, centrifuged at $12000 \mathrm{rpm}$ for $20 \mathrm{~min}$ at $4{ }^{\circ} \mathrm{C}$, and the supernatants were detected by HPLC. Bars indicate the range of assay results from three different batches. Figure S4. pH profile of StUSP catalysis in whole cells. Reactions were performed in a mixture consisting of $2 \mathrm{mM} \mathrm{G1P}, 3 \mathrm{mM}$ UTP, $20 \mathrm{mM} \mathrm{Mg}^{2+}, 50 \mathrm{mM}$ sodium phosphate, and about BL21-TmaGP cells (12.5 mg DCW per milliliter), at various $\mathrm{pH}$ values in the range 2.5-12. Bars indicate the range of assay results from three different batches. Figure $\mathbf{S 5}$. Effect of reaction time on UDP-Glc formation. Reactions were performed in a mixture consisting of $2 \mathrm{mM} \mathrm{G1P}, 3 \mathrm{mM}$ UTP, $20 \mathrm{mM} \mathrm{Mg}^{2+}, 50 \mathrm{mM}$ sodium phosphate ( $\mathrm{pH}$ 9.0), and about BL21-TmaGP cells (12.5 mg DCW per milliliter), for $0,5,10,30,40,60,80,120,180$ and 240 min, respectively. Bars 
indicate the range of assay results from three different batches. Figure $\mathbf{S 6}$ Activity assays of whole cells expressing StUSP by quantity of cells added. Glc-1-P (2 mM) was respectively incubated with $0,0.09,0.23,0.46,0.91,1.37$ and $1.82 \mathrm{mg}$ (DCW) BL21-TmaGP cells in a 320- $\mathrm{LL}$ mixture consisting of $3 \mathrm{mM}$ UTP, $20 \mathrm{mM} \mathrm{Mg}{ }^{2+}$ and $50 \mathrm{mM}$ sodium phosphate (pH9.0). All experiments were repeated three times. About $4.28 \mathrm{~g} \mathrm{DCW}$ of StUSP-expressing cells/L reaction mixture was determined to be the most suitable value for UDP-Glc formation. Figure S7. Optimization of usage of UTP in UDP-Glc formation by BL21-TmaGP cells. BL21-TmaGP cells ( $4.3 \mathrm{mg}$ DCW per milliliter)) were incubated with the substrate UTP, the concentration of which was varied from 0 to $6 \mathrm{mM}$, in a mixture containing $2 \mathrm{mM} \mathrm{G1P}, 20 \mathrm{mM}$ $\mathrm{Mg}^{2+}$ and $50 \mathrm{mM}$ sodium phosphate ( $\mathrm{pH}$ 9.0). Bars indicate the range of assay results from three different batches. Figure $\mathbf{8 8}$. Analysis of PiUDH catalysis in whole-cells by temperature. BL21-PiUDH cells $(17.5 \mathrm{mg} / \mathrm{mL}$ DCW) were incubated in a mixture consisting of $2.3 \mathrm{mM}$ UDP-Glc, $1.5 \mathrm{mM}$ $\mathrm{NAD}^{+}$and $200 \mathrm{mM}$ sodium phosphate (pH10) at 50, 60, 65, 70, 75, 80, and $85^{\circ} \mathrm{C}$, respectively. The reactions were terminated by chilling on ice for 5 min, and then centrifuged at $12000 \times g$ for 20 min at $4^{\circ} \mathrm{C}$, and the supernatants were detected by HPLC. Bars indicate the range of assay results from three different batches. Figure S9. pH profile of production of UDP-GICA by whole cells expressing PiUDH. Reactions were performed in a mixture consisting of $2.3 \mathrm{mM}$ UDP-Glc, $1.5 \mathrm{mM} \mathrm{NAD}{ }^{+}, 200 \mathrm{mM}$ sodium phosphate, and $17.5 \mathrm{mg} / \mathrm{mL}$ (DCW) BL21-PiUDH cells at $\mathrm{pH}$ values in the range $2.5-13$. Bars indicate the range of assay results from three different batches. Figure S10. Effect of reaction time on UDP-GlcA formation by whole cells expressing PiUDH. Reactions were performed in a mixture consisting of $2.3 \mathrm{mM}$ UDP-Glc, $1.5 \mathrm{mM} \mathrm{NAD}+200 \mathrm{mM}$ sodium phosphate ( $\mathrm{pH} 10)$, and BL21PiUDH cells (17.5 mg DCW per milliliter), for $0,10,20,30,40,60,90,120,150$, and $180 \mathrm{~min}$, respectively. Figure $\mathbf{S 1 1}$. Optimization of usage of $\mathrm{NAD}^{+}$in whole-cell catalysis by cells expressing PiUDH. BL21-PiUDH cells $(17.5 \mathrm{mg}$ DCW per milliliter) were incubated with the cofactor $\mathrm{NAD}^{+}$, the concentration of which was varied from 0 to $1.2 \mathrm{mM}$, in a mixture containing $2.3 \mathrm{mM}$ UDP-Glc and $200 \mathrm{mM}$ sodium phosphate (pH9.0) for $3 \mathrm{~h}$. Bars indicate the range of assay results from three different batches. Figure $\mathbf{S 1 2}$. Activity assays of BL21-PiUDH-TkNOX cells by quantity of cells added. Bars indicate the range of assay results from three different batches.

\section{Acknowledgements}

We are grateful to Prof. Hong-Zhi Cao and Prof. Chun-Hui Liu of Shandong University for many helpful discussions and suggestions.

\section{Authors' contributions}

JS designed and coordinated the work. DM carried out the experiments. RD and ML carried out the HPLC analysis. LC and JH carried out NOX experiments. FL and FW conducted the fermentation. YS conducted the TLC analysis. JS and DM wrote the manuscript. All authors read and approved the final manuscript.

\section{Funding}

The National Natural Science Foundation of China (Project No. 31770845), the Projects of Science and Technology Department of Shandong Province (Project No. 2018CXGC1402), and the Research Funds for QILU Young Scholars of SDU, Key Laboratory of Chemical Biology (Ministry of Education) Open Projects Fund.

\section{Ethics approval and consent to participate}

Not applicable.

\section{Consent for publication}

Not applicable.

\section{Competing interests}

The authors declare that they have no competing interests.

\section{Author details}

${ }^{1}$ Key Laboratory of Chemical Biology of Natural Products (Ministry of Education), School of Pharmaceutical Sciences, Shandong University, Jinan 250012, China. ${ }^{2}$ Key Laboratory of Biopharmaceuticals, Shandong Academy of Pharmaceutical Sciences, Jinan 250101, China. ${ }^{3}$ State Key Laboratory of Microbiology, Shandong University, Jinan 250100, China. ${ }^{4}$ National Glycoengineering Research Center, Shandong University, Jinan 250012, China.
Received: 1 April 2019 Accepted: 26 June 2019

Published online: 01 July 2019

\section{References}

1. Varki A, Cummings RD, Esko JD, Freeze HH, Stanley P, Bertozzi CR, et al. Essentials of glycobiology, 2nd edition. Cold Spring Harbor Laboratory Press: Cold Spring Harbor; 2009. http://www.ncbi.nlm.nih.gov/books/ NBK1908/. Accessed 14 Jan 2019.

2. Tukey RH, Strassburg CP. Human UDP-glucuronosyltransferases: metabolism, expression, and disease. Annu Rev Pharmacol Toxicol. 2000;40:581-616.

3. Decker D, Kleczkowski LA. UDP-sugar producing pyrophosphorylases: distinct and essential enzymes with overlapping substrate specificities, providing de novo precursors for glycosylation reactions. Front Plant Sci. 2019;9:1822. https://doi.org/10.3389/fpls.2018.01822/full.

4. Chemical biology of glycoproteins. 2017. https://pubs.rsc.org/en/conte nt/ebook/978-1-78262-333-5. Accessed 14 Jan 2019.

5. Xu Y, Fan $Y$, Ye J, Wang F, Nie Q, Wang L, et al. Successfully engineering a bacterial sialyltransferase for regioselective a2,6-sialylation. ACS Catal. 2018:8:7222-7.

6. Badri A, Williams A, Linhardt RJ, Koffas MA. The road to animal-free glycosaminoglycan production: current efforts and bottlenecks. Curr Opin Biotechnol. 2018;53:85-92.

7. Yu H, Chen X. One-pot multienzyme (OPME) systems for chemoenzymatic synthesis of carbohydrates. Org Biomol Chem. 2016;14:2809-18.

8. Wen L, Zheng Y, Jiang K, Zhang M, Kondengaden SM, Li S, et al. Twostep chemoenzymatic detection of $\mathrm{N}$-acetylneuraminic acid-a(2-3)galactose glycans. J Am Chem Soc. 2016;138:11473-6.

9. Zhang J, Chen C, Gadi MR, Gibbons C, Guo Y, Cao X, et al. Machine-driven enzymatic oligosaccharide synthesis by using a peptide synthesizer. Angew Chem Int Ed. 2018;57:16638-42.

10. Wang PG, Zhang J, Chen C, Gadi MR, Gibbons C, Cao X, et al. Machine driven enzymatic oligosaccharide synthesis by a peptide synthesizer. Angew Chem Int Ed. 2018. https://doi.org/10.1002/anie.201810661.

11. Ninomiya T, Sugiura N, Tawada A, Sugimoto K, Watanabe H, Kimata K. Molecular cloning and characterization of chondroitin polymerase from Escherichia coli strain K4. J Biol Chem. 2002;277:21567-75.

12. Williams KJ, Halkes KM, Kamerling JP, DeAngelis PL. Critical elements of oligosaccharide acceptor substrates for the Pasteurella multocida hyaluronan synthase. J Biol Chem. 2006;281:5391-7.

13. Green DE, DeAngelis PL. Identification of a chondroitin synthase from an unexpected source, the green sulfur bacterium Chlorobium phaeobacteroides. Glycobiology. 2017;27:469-76.

14. Wang T-T, Zhu C-Y, Zheng S, Meng C-C, Wang T-T, Meng D-H, et al. Identification and characterization of a chondroitin synthase from Avibacterium paragallinarum. Appl Microbiol Biotechnol. 2018;102:4785-97.

15. Otto NJ, Green DE, Masuko S, Mayer A, Tanner ME, Linhardt RJ, et al. Structure/function analysis of Pasteurella multocida heparosan synthases: toward defining enzyme specificity and engineering novel catalysts. J Biol Chem. 2012;287:7203-12.

16. Xu Y, Chandarajoti K, Zhang X, Pagadala V, Dou W, Hoppensteadt DM, et al. Synthetic oligosaccharides can replace animal-sourced low-molecular weight heparins. Sci Transl Med. 2017;9:eaan5954.

17. XuY, Cai C, Chandarajoti K, Hsieh P-H, Li L, Pham TQ, et al. Homogeneous low-molecular-weight heparins with reversible anticoagulant activity. Nat Chem Biol. 2014;10:248-50.

18. Li J, Su G, Liu J. Enzymatic synthesis of homogeneous chondroitin sulfate oligosaccharides. Angew Chem. 2017;129:11946-9.

19. Fu X, Shang W, Wang S, Liu Y, Qu J, Chen X, et al. A general strategy for the synthesis of homogeneous hyaluronan conjugates and their biological applications. Chem Commun. 2017;53:3555-8.

20. Rejzek M, Hill L, Hems ES, Kuhaudomlarp S, Wagstaff BA, Field RA. Chapter Seven_Profiling of sugar nucleotides. In: Imperiali B, editor. Methods in enzymology. Academic Press: New York; 2017. p. 209-38. http://www. sciencedirect.com/science/article/pii/S0076687917301623.

21. Ito J, Herter T, Baidoo EEK, Lao J, Vega-Sánchez ME, Michelle Smith-Moritz A, et al. Analysis of plant nucleotide sugars by hydrophilic interaction liquid chromatography and tandem mass spectrometry. Anal Biochem. 2014;448:14-22. 
22. Chen Y, Li Y, Yu H, Sugiarto G, Thon V, Hwang J, et al. Tailor design and synthesis of heparan sulfate (HS) oligosaccharide analogs using sequential one-pot multienzyme (OPME) systems. Angew Chem Int Ed Engl. 2013;52:11852-6.

23. Muthana MM, Qu J, Xue M, Klyuchnik T, Siu A, Li Y, et al. Improved one-pot multienzyme (OPME) systems for synthesizing UDP-uronic acids and glucuronides. Chem Commun. 2015;51:4595-8.

24. France SP, Hepworth LJ, Turner NJ, Flitsch SL. Constructing biocatalytic cascades: in vitro and in vivo approaches to de novo multi-enzyme pathways. ACS Catal. 2017;7:710-24.

25. Adams MWW, Kelly RM. Finding and using hyperthermophilic enzymes. Trends Biotechnol. 1998;16:329-32.

26. Zhang Z, Tsujimura M, Akutsu J, Sasaki M, Tajima H, Kawarabayasi Y. Identification of an extremely thermostable enzyme with dual sugar-1-phosphate nucleotidylyltransferase activities from an acidothermophilic archaeon, Sulfolobus tokodaii strain 7. J Biol Chem. 2005;280:9698-705.

27. Zhou W, You C, Ma H, Ma Y, Zhang YHP. One-pot biosynthesis of high-concentration a-glucose 1-phosphate from starch by sequential addition of three hyperthermophilic enzymes. J Agric Food Chem. 2016:64:1777-83.

28. Satomura T, Kusumi K, Ohshima T, Sakuraba H. Identification and characterization of UDP-glucose dehydrogenase from the hyperthermophilic archaon, Pyrobaculum islandicum. Biosci Biotechnol Biochem. 2011;75:2049-51.

29. Xi Wu, Hiroki Kobori, Izumi Orita, Chong Zhang, Tadayuki Imanaka, XinHui Xing, et al. Application of a novel thermostable NAD(P)H oxidase from hyperthermophilic archaeon for the regeneration of both $N A D^{+}$ and NADP+ ${ }^{+}$. Biotechnol Bioeng. 2011;109:53-62.

30. Krefft D, Papkov A, Zylicz-Stachula A, Skowron PM. Thermostable proteins bioprocesses: the activity of restriction endonuclease-methyltransferase from Thermus thermophilus (RM.TthHB27I) cloned in Escherichia coli is critically affected by the codon composition of the synthetic gene. PLoS ONE. 2017;12:e186633.

31. Zylicz-Stachula A, Zolnierkiewicz O, Sliwinska K, Jezewska-Frackowiak J, Skowron PM. Modified 'one amino acid-one codon' engineering of high GC content Taqll-coding gene from thermophilic Thermus aquaticus results in radical expression increase. Microb Cell Fact. 2014;13:7.

32. Yin F-X, Wang F-S, Sheng J-Z. uncovering the catalytic direction of chondroitin AC exolyase from the reducing end towards the non-reducing end. J Biol Chem. 2016;291:4399-406.

33. Zheng S, Hou J, Zhou Y, Fang H, Wang T-T, Liu F, et al. One-pot two-strain system based on glucaric acid biosensor for rapid screening of myoinositol oxygenase mutations and glucaric acid production in recombinant cells. Metab Eng. 2018;49:212-9.

34. Eixelsberger T, Nidetzky B. Enzymatic redox cascade for one-pot synthesis of uridine $5^{\prime}$-diphosphate xylose from uridine 5 '-diphosphate glucose. Adv Synth Catal. 2014;356:3575-84.

\section{Publisher's Note}

Springer Nature remains neutral with regard to jurisdictional claims in published maps and institutional affiliations.
Ready to submit your research? Choose BMC and benefit from:

- fast, convenient online submission

- thorough peer review by experienced researchers in your field

- rapid publication on acceptance

- support for research data, including large and complex data types

- gold Open Access which fosters wider collaboration and increased citations

- maximum visibility for your research: over $100 \mathrm{M}$ website views per year

At BMC, research is always in progress.

Learn more biomedcentral.com/submissions 